\title{
Correction to: Development of an Intervention Aimed at Increasing Awareness and Acknowledgement of Victimisation and Its Consequences Among People with Severe Mental IIIness
}

\author{
Wendy M. M. Albers ${ }^{1,2}$ (D) Yolanda A. M. Nijssen ${ }^{1,3} \cdot$ Diana P. K. Roeg $^{1,2,4} \cdot$ Inge M. B. Bongers $^{1,4} \cdot$ Jaap van Weeghel $^{1,3,5}$
}

Published online: 17 February 2021

(c) Springer Science+Business Media, LLC, part of Springer Nature 2021

\section{Correction to: Community Mental Health Journal https://doi.org/10.1007/s10597-021-00776-y}

The original version of this article unfortunately contained errors in text.

In article, the text which was blinded as "XXX" during review process was published incorrectly as such. But, every 'XXX' should be 'Victoria'.

The original article has been corrected.

The original article can be found online at https://doi.org/10.1007/ s10597-021-00776-y.

Wendy M. M. Albers

w.m.m.albers@tilburguniversity.edu

1 Tranzo Scientific Center for Care and Wellbeing,

Tilburg School of Social and Behavioral Sciences,

Tilburg University, PO Box 90153, 5000 LE Tilburg,

The Netherlands

2 Kwintes Housing and Rehabilitation Services, Laan van Vollenhove 3213, 3706 AR Zeist, The Netherlands

3 Parnassia Psychiatric Institute, Monsterseweg 93, 2553 RJ Den Haag, The Netherlands

4 GGzE Mental Health Care Institute Eindhoven, Dr. Poletlaan 40, 5626 ND Eindhoven, The Netherlands

5 Phrenos Center of Expertise, Da Costakade 45, 3521 VS Utrecht, The Netherlands
Publisher's Note Springer Nature remains neutral with regard to jurisdictional claims in published maps and institutional affiliations. 